\title{
Ecologies of Leisure: Reimagined Architectures and Landscapes of Leisure and Infrastructure
}

Carla Aramouny

\section{LANDSCAPE URBANISM}

ABSTRACT - The research detailed in this paper revolves around an ecological and spatial exploration for a derelict coastal area in Lebanon. It frames the possibility for an agile ecological approach to design, one that builds upon the latent derelict aspects and persisting disconnections in this specific area and that reimagines a potential new reality intermeshing the natural with the human and the infrastructural with the architectural. Within the format of a research undergraduate studio, the approach and work discussed here present possible synthetic scenarios for coastal developments in Lebanon, and suggest alternative production, programmatic, and ecological strategies.

Keywords: design pedagogy, ecology, hybrid design, infrastructure, leisure architecture

"If there is to be a 'new urbanism' it will not be based on the twin fantasies of order and omnipotence; it will be the staging of uncertainty; it will no longer be concerned with the arrangement of more or less permanent objects but with the irrigation of territories with potential; ... it will no longer be about meticulous definition, the imposition of limits, but about expanding notions, denying boundaries, not about separating and identifying entities, but about discovering unnamable hybrids."

(Rem Koolhaas) ${ }^{1}$

What other possible realities are there for the derelict coastline of Lebanon? What modes of ecologies, usages, and re-appropriations could be 
imagined? Can latent disconnections, evident in the coastal area as a result of its disordered history and uncontrolled sprawl, become the agency for change? These reflections frame a position on design from an eco-spatial perspective, one that inherently relies on the disparate existing ecologies of the Lebanese coast and its varying spatial modalities and usages.

In the framework of an advanced vertical studio, the quest for alternative environments instigated the investigation and the drive to look towards new sites of opportunity, away from the typicality of investigating Beirut. Students were asked to delve into a somewhat unfamiliar area, that of Zouk, a coastal peri-urban site of various dichotomies with untapped ecological and programmatic potential. The imbedded clashes observed in that coastal area happen at many levels, at the level of its disconnection from its larger context, and at the level of the various natures persisting in it, from man-made and natural landscapes, suburbanized fabric and abandoned industrial spaces, to polluting spaces of production and communes of leisure.

\section{THE LEBANESE COAST AND THE SITE'S HISTORY}

Lebanon's coastline on the Mediterranean is one of its main geo-morphological features, a thin strip flanked by Mount Lebanon of around $500 \mathrm{~m}$ [0.31 mi.] in width, stretching along the entire length of the country for $240 \mathrm{~km}$ [149 mi.]. The coast from the south to the north is geologically rich and diverse, varying between sandy beaches and shallow waters, to rocky beaches with deep water coastal edge. ${ }^{2}$ Although historically it was mostly developed as agricultural fields for citrus, olives, and banana production, which stretched between its main coastal cities, its productive value shifted since the 1950s towards real estate development, where private developments were built over the public sphere and altered the coast's natural ecology. ${ }^{3}$ After a 1983 decree which permitted real-estate companies to develop the coast, large scale high-end developments were put forward through special decrees, especially during and after the civil war ${ }^{4}$ and extending outside the peripheries of Beirut. ${ }^{5}$ Developments such as Linord, Solidere Beirut Waterfront, and Dbayeh Waterfront, offered only high-end residential and commercial programs, and were further planned on reclaimed land, detrimentally re-shaping the coastal morphology and ecology. ${ }^{6}$ However, more than 85 percent of the Lebanese territory, including its coast, remains today without urban planning directives. ${ }^{7}$ Moreover, the coastal edge is legally public domain, however the continuous and illegal privatization of the coast by adjacent lots with illegal landfills, resulted in large portions of the coast, especially in the sprawl area surrounding Beirut, to be inaccessible to the public. $^{8}$

Beirut, the capital and the country's biggest city, has a large urban fabric extending continuously beyond the limits of its municipal boundaries. The greater Beirut suburbs include dense agglomerations spreading out of the city and sprawling over the adjacent coastline and mountains.

Land use and activities at the coast specifically north and south of the city, 
incorporate mixes of industrial, agricultural, and touristic functions, which are separated from the residential neighborhoods inland by the main coastal highway. From Beirut's commercial port to the north, stretches of industrial zones, commercial buildings, fuel stations, to high-end developments and the mostly vacant Dbayeh Waterfront city, line the edge where the sea is mostly inaccessible and polluted, as it is intermittently privatized by these developments and heavily contaminated by adjacent industries.

The Zouk coastal strip, which falls under the two towns of Zouk Mosbeh and Zouk Mikael, is situated in this northern stretch, in the Keserwan district $14 \mathrm{~km}$ [8.7 mi.] away from Beirut. The morphologically protruding rock of the Nahr El Kalb river, historically created a boundary between Keserwan, a predominantly Christian area, and the adjacent Dbayeh suburb and Beirut. This coastal strip is cut from the larger municipal limits of Zouk Mosbeh and Zouk Mikael by the main coastal highway (Fig. 1). The area forms a very particular zone where the clash of the natural coastline, private touristic developments, agricultural history, and industrial zoning, produce varied environments with dysfunctional in-between spaces. The area prior to the 1960s was vastly agricultural in nature directly adjacent to the delta of the Nahr el Kalb river ${ }^{9}$ and known for its mulberry and sugar cane plantations that were later replaced by citrus and banana trees (Fig. 2), and where local famers and their families had an immediate connection to the sandy beach. In 1956, a gas power plant was built on this coastline, ${ }^{10}$ which was later adapted to fuel in the ' 80 s with two large polluting exhaust towers creating a main visual intrusion on the coast.

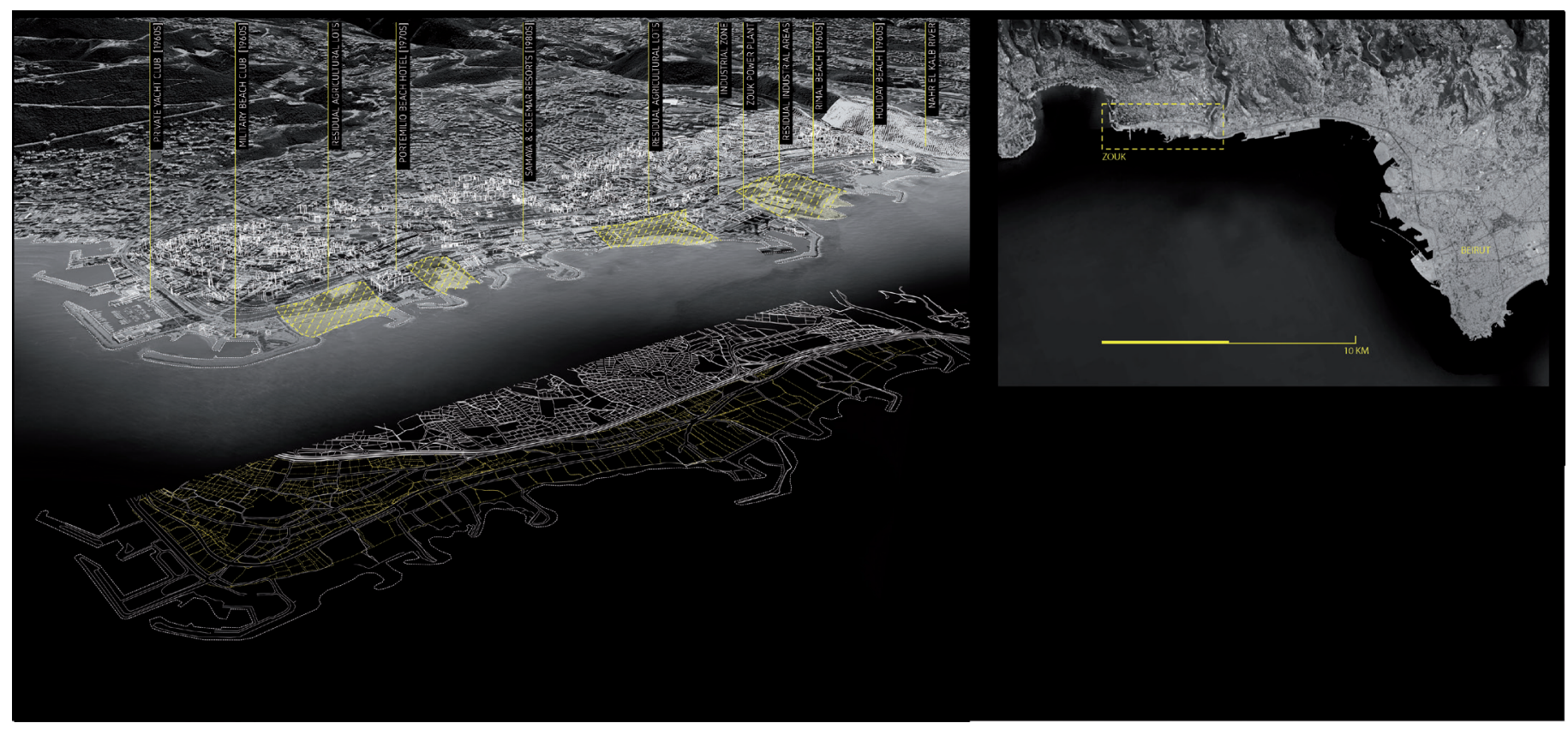

Figure 1. Zouk coast and its context. 

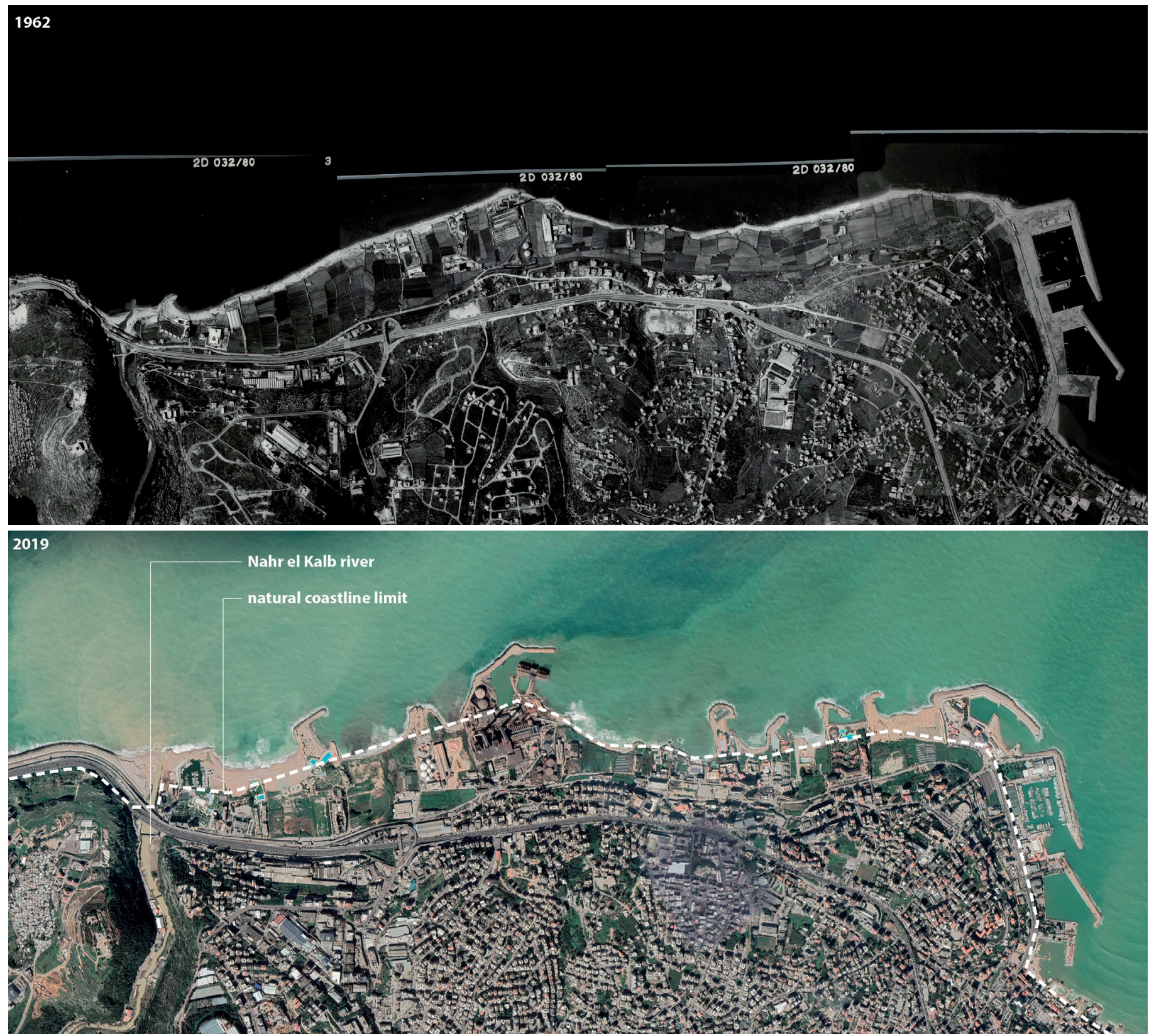

Figure 2. The area's mutation from 1962 till today.

Shifts in planning and zoning decrees from the early '70s onwards, ${ }^{11}$ changed the nature of the coast, which was predominantly agricultural, to incorporate industrial and touristic zoning. This allowed new types of programs to emerge, and start to embed themselves in between the agricultural fields, from touristic private resorts to heavy industries and production plants. Lack of control during and after the civil war in addition to corruption, led to several illegal developments on this coastal strip. Private beach resorts proliferated from the ' 60 s till the late ' 80 s, the majority of which extended over the public maritime domain, landfilling the sea, and illegally prohibiting coastal access to the general public. The resorts 
operated as leisure destinations, where people gain access through buying or renting a chalet in the complex. Each resort functioned as a separate entity, fully operational with its own infrastructure, and its own sports, leisure, and food and beverage facilities. The resorts became pseudovillages and sometimes permanent households by the sea, catering to an influx of people fleeing the ravages of the civil war in Beirut, as a safe and proximate escape. This influx also resulted in a sprawl of uncontrolled urbanization of the larger context of Zouk. The rapid and uncontrolled development of the area, continuing well into the post war period, led to a continuous abuse of the natural ecology of the coastline, and an ensuing tapestry of disparate programs of industry, energy, and tourism, operating mostly in silos, without any interaction among them, while the area's agricultural fields shrank considerably in the years that followed.

The power plant had a detrimental impact on the coastal area, which currently suffers from extensive air and water pollution. ${ }^{12}$ Although the local government had initiated plans to shut down the facility due to its detrimental impact and the inefficiency of its production, it still remains today, however operated by rented power ships that dock in its waters. The area's environmental decline is further exacerbated by the adjacent polluted river, from illegal waste and industrial dumping, leading to further marginalization and abandonment of the area by the community. The area's decline has also affected the agricultural fields, industries, and private beach resorts that lost their once vibrant popularity and now most sit in a state of limbo. Mostly vehicular in nature, few pedestrian flows connect the different disparate locations of this coast, only confined to a few commercial strips. The beach strip, also heavily polluted with litter and dumped waste, is barely accessible due to the forced privatization.

\section{THE ECOLOGY OF ZOUK AND ITS SCALES OF EXCLUSION}

The term ecology, as observed in the context of Zouk, is understood from the material sense, as different embedded systems that encompass human, natural, or technological aspects. In his reflections on Reyner Banham's Los Angeles: The Architecture of Four Ecologies (1971), Stan Allen ${ }^{13}$ uses the term "material ecologies" to differentiate ecology from the necessarily "natural" and suggests instead a more synthetic reading that intersects the natural and the artifice.

From a similar framework, the area of Zouk is understood through its different material ecologies, seen as disparate and co-existing systems that have kept the area in a derelict condition.

Those include the industrial and often abandoned factories, the interstitial agricultural fields, some of which are abandoned, the power plant facility, and the private beach resorts with sports and leisure activities. Each one of these programs is understood as a separate ecology, as it incorporates its own systems, logistics, connections and operations. Each ecology loosely 
operates on its own, connected only through the road system to the main highway, without any necessary interaction between the adjacent zones, beyond sharing bordering limits. The underlying natural ecology of the area also forms another layer of this reading, appearing through the occasional residual terrain, or at the narrow coastal edge by the sea, or by the river and its riparian edge. Heavily polluted, derelict or inaccessible, most of the remaining natural sites are excluded from any form of productivity. At this micro scale, the Zouk coast presents a case of exclusion between the different ecologies and the derelict landscapes (Fig. 3). Such disconnections have led to a detrimental impact on a natural and once productive landscape as the climax of private to public clash and of agriculture/industrial to leisure clash, has led to the continuous takeover of private usages and exclusive leisure over other modes of ecologies. This was particularly advantaged by the lack of state control or strict application of any urban planning directives during and after the war period.

Another scale of disconnection or exclusion happens more at the macro scale, between the coastal area and its suburban vicinity. The coastal zone is cut off from its residential and industrial counterparts on the adjacent slopes by the main coastal highway that forms a physical barrier (Fig. 4). The highway runs in parallel to the coastal strip, with little lateral connections connecting the coastal zone and the suburbs, for either pedestrian or vehicular flows. As such the strip connects more directly to vehicular flow coming from the highway, serving more readily visitors from different areas around the Keserwan district and Lebanon in general.

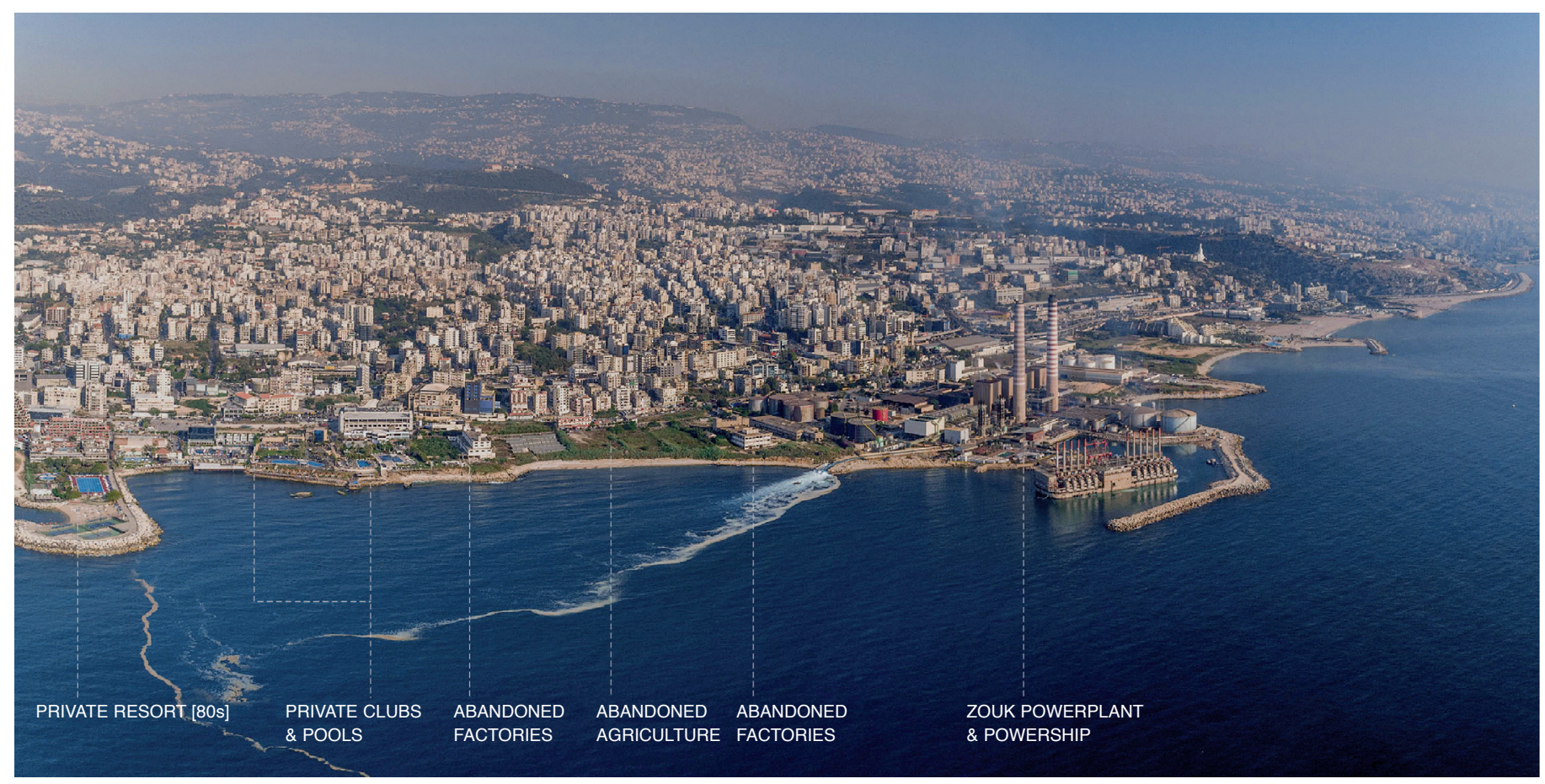

Figure 3. Zouk aerial with powerplant and residual areas. 


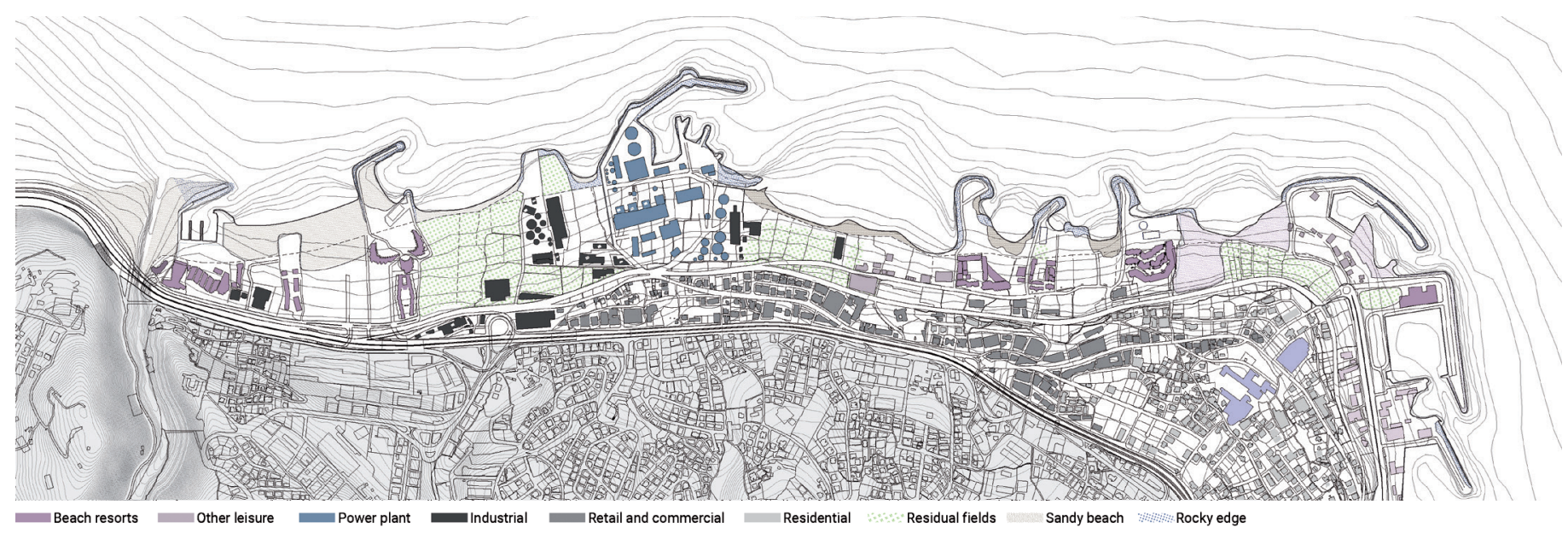

Figure 4. Area analysis and land use.

However, due to the exclusivity of the beach resorts, pollution, and the derelict state of the industrial and agricultural facilities, the area remains semi-isolated and desolate.

Although in this decrepit state, the area still holds further potential in its location and relative proximity to Beirut. Despite these different separations and the derelict state of the area, the different material ecologies present an accumulation of potential spaces and possible productive areas. In his essay "Terrain Vague" (1995), Ignasi de Solà-Morales ${ }^{14}$ presents the "vague" or the undefined space, as one which designates both the vacant and the free, where absence yields the promise of possibility. The link thus between the derelict and a new potential is important, however if the new possibility for the area is evolved out of its existing environments rather than superimposed over them.

\section{AGILE ECOLOGY}

From these different readings of the area, the ambition of the research studio was to reimagine another possible scenario of development for that area, as a distinct opposite to the typical real estate driven projections for the coast of Lebanon, discussed above. The purpose was to revive the isolated and marginalized area, reconnect it to its larger context, and to transform and build upon its latent potentials in a symbiotic systemic ecology that fuses architecture, landscape, and infrastructure through new programs of leisure and production. From a design methodology point of view, ecology is considered as an operative binding system, where the various natures evident on site form the basis for a synthetic new environment, and where the different layers of the proposed new spatial environment connect synergistically and fluidly.

This attitude towards "ecology" in general stemmed from the necessity to consider ecology not only from its natural connotation, but also from its 
understanding as corelating system between environment, organisms, and people. Thus, as an operative term, ecology can be considered as a systemic manifestation encompassing natural and non-natural environments. Mohsen Mostafavi ${ }^{15}$ frames the ecological with the urban as necessary conjoint systems that need to be addressed simultaneously through ecological urbanism as a model, where ecosystems and inherent resources, both human and non-human, form the "basis for a new form of creative imagining."

James Corner ${ }^{16}$ further points to a shift in design practices towards "pliant" systems that respond and adapt to the changing fluxes and dynamic manifestations of today's world. He positions ecology as a regulatory framework that has the inherent capacity to address underlying complexities and perform as a fluid field where architecture, landscape, planning, and ecology become strategically interconnected components, creating what he calls a "new kind of synthetic imagination" for urban projects.

Within this model, it is essential to position architecture, the urban context, and the natural landscape as synergetic agents. Michelle Laboy ${ }^{17}$ proposes that the autonomy of architecture in its historical discourse moved it away from engaging critically with the city or landscape as it centered around the study of architectural typologies. Her position reclaims the necessity for a reconnection of architecture to landscape and the environment at large, both the natural and the built, through critical hybrid practices that address ecological performance and inherent relationships where "architecture becomes an active agent in restoring or constructing urban ecologies."

In more recent shifts in landscape and architecture design, we observe a move towards more symbiotic strategies between natural systems and non-natural systems, where behaviors and biological organisms become design agents. Anna Souter ${ }^{18}$ proposes "rewilding" as a necessary act that is essentially non-conservational, where "agency is passed on from the human to the non-human," and where landscape becomes self-willed, allowing its change, evolution, and impact on the surrounding environment. In a sense, it is to recognize the prospective of an untamed natural environment where human intervention only serves to instigate its propagation rather than control it.

Kate Orff ${ }^{19}$ further advocates for more informed and sustainable spatial practices, that must address the challenges of the time by revealing and tackling the invisible problematics affecting our habitat from bacterial toxicities to other concealed environmental concerns and flaws. Through her work, she situates an informed new ecological practice towards notions of revival ${ }^{20}$ and cohabiting, ${ }^{21}$ where revival involves the acknowledgement of current anthropogenic landscapes as points of departure for new landscape models, and cohabiting involves the simultaneous and mutual sharing of the natural and built habitats between the human and the nonhuman. In a way, this concedes of a symbiotic relation between reimagined and actively performing natural ecologies and the man-made built habitat. 
Framed within these ecological perspectives, the approach for this design studio thus suggests ecology as a design system and moves towards more agile alternatives that build upon raw and latent qualities in the coast. As such, we look specifically at the potential of the derelict and raw environments evident in the site, both the natural and non-natural, and in the potential of redevising the boundaries of these latent systems as agile "open" alternatives that change the way the site has previously operated. It is not to purely fix or replace but rather to re-imagine another possible life for this coast, one that allows the simultaneous existence and crosshybridization of the different natural, leisure, and production capacities evident there.

The studio thus set out towards tackling existing modes of disconnection, in-between sites of potential, and newly imagined alternative operations that partake architecture, infrastructure and the natural environment.

\section{OTHER FICTIONS: AGILE STRATEGIES}

Within the scales of disconnection evident in the site, and from an agile design framework, the studio proceeded towards creating ecological hybrids that propose new unifying natures of leisure, infrastructure, and production. The pedagogical approach pushed for evaluating the site as a continuous field rather than distinct plots, using theoretical readings, iterative abstract models, and composite representations. Each project, developed by a group of two students, involved scalar projections of macro and mid-scale interventions, which included intermeshed architectural, infrastructural, and landscape components. The scalar approach started from the macro strategy for the overall site, stratifying the site's multiple layers and existing programs, and then developed towards the medium scale in a specific site of focus.

Students researched the various shaping layers of the area, including history, ownership, and zoning, landscape and coastal typologies, modes of formal and informal leisure, existing infrastructural systems, production and agricultural conditions, and pollution's devastating impact. Each strategy was developed as an operative system, a field condition, that encompasses architectural typological investigations, landscape and productive systems, and infrastructure.

Three main driving strategies at the different imbedded scales guided each student project at ecological, morphological, and programmatic levels: renaturalization, transformation of the in-between, and agile programing. The first strategy, renaturalization, included re-instigating lost coastal ecologies and reintegration of native landscape types. Students approached new landscape interventions as necessarily active and productive systems able to have a performative role for the expanded environment (the built and the unbuilt). In the second strategy, in-between sites were looked at as potential 
connectors and as thresholds of transformations that can manipulate the various differences into an operative fusion. They were observed as sites of interstitial opportunity, where morphological and spatial transformations allow potential synergies. Instead of shutting off one program from the next, reactivating the in-between sites and redesigning existing boundaries as spatial connectors can reconnect the disintegrated area.

With agile programing as a third design strategy, alternative usages and more current types of activities were imagined from existing ones. This included new forms of contemporary leisure that build on the site's existing formal and informal usages, more adaptable agricultural practices and new types of production, and the inclusion of more sustainable energy, water, and transportation systems.

The emergent hybrid results by the students each focused on a specific lens of operation, reframing the three aforementioned strategies through distinctive agendas and thematics. Furthermore, the studio pedagogy oscillated between visual experimentation and abstract "field" models to translate the different strategies and site dynamics at each of the scales of operation. The abstract models formed the in-between phase, the translation from research and analysis into the first formal and conceptual interpretations (Fig. 5). Through the iterative models, students worked on two main scales of operation, as previously mentioned. The macro scale involved the strategic reimagining of the area through its systems and infrastructure, and the mid-scale further developed the iterations as formal armatures that include spatial, landscape, and programmatic intersections. From these two scales, the students then developed fully the more micro architectural scale, detailing its spatial components, material, structure, and landscape attributes.

The first student group focused on coastal renaturalization and landscape as a productive filtering system. They looked at the various forms of toxicity
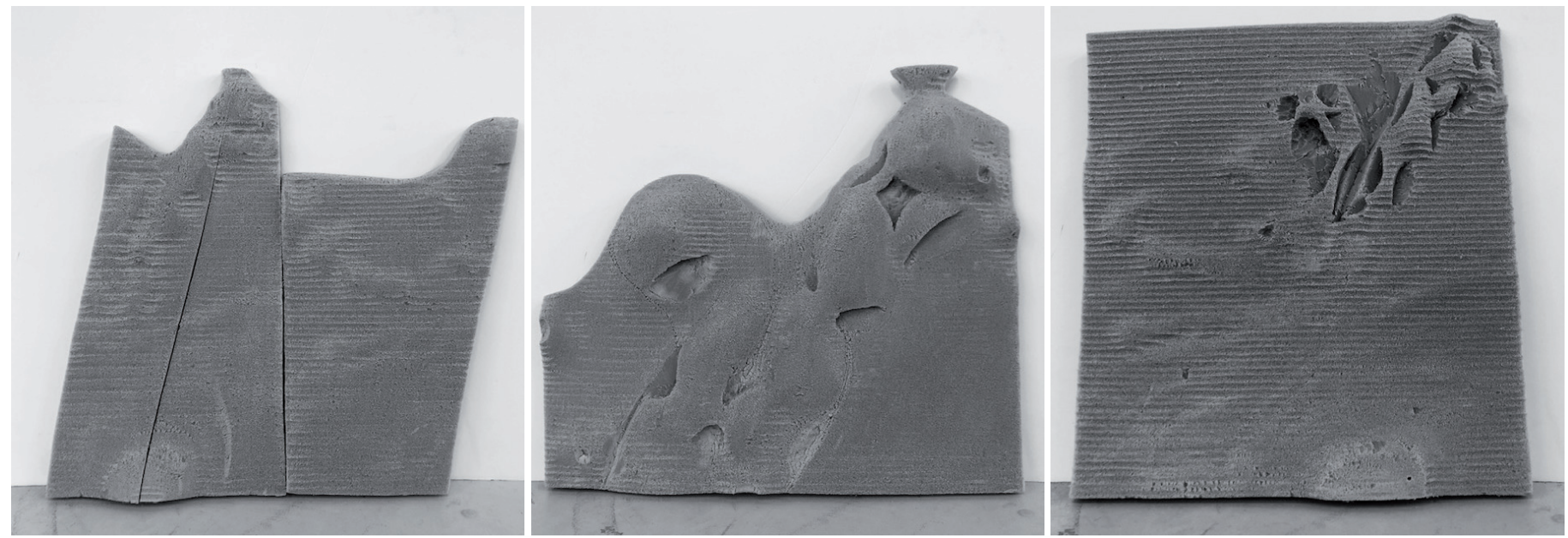

Figure 5. Abstract iterative models as field conditions. 
affecting the area, and the drift of sea and adjacent river pollution due to wave currents towards the coast. They approached the site with an overall organizing scheme that responds to these latent toxicities and their impact on local biodiversity to create active landscape infills and coastal edge reformation. (Fig. 6). Their scheme integrated programs for beach leisure, water filtration station, a marketplace and library, while inserting agricultural landscapes and bioswales that can help clean water runoffs before reaching the sea. Their strategy included creating barriers and platforms built on shallow water, that would work against the current to create protected zones and allow algae growth and sea urchin colonies (Fig. 7). These elevated platforms serve also as public leisure hybrid piers with the upper deck allowing promenades and swimming, and the lower level integrating different spaces for the library.

The second project used water as a guiding design system, where existing water flows formed the starting point of the design. The students looked at the existing natural aquifers in the hill, the adjacent contaminated Nahr El Kalb river, the rainwater runoff on the road infrastructure, and the resulting pollutants that affect the site from organic waste to plastic residues (Fig. 8). These various systems formed the basis for designing an ecological landscape and water infrastructure, that reforms the coastal area as a biodiverse productive field, and that connects the upper hill area to the lower coast through water channels, filtration, and collection points. At the macro scale (Fig. 9), their vision encompassed a hybrid ecological field integrating these water systems with agriculture, filtering landscapes, and renewable energy stations. Programs such as a public park and marine museum, a public aquarium, and agri-tourism, allowed both leisure and productive capacities. Manipulations of the coast resulted in new delta conditions that would re-allow biodiverse flora and fauna to grow. At the mid-scale (Fig. 10), their water collection scheme benefited from the adjacent slopes to collect rainwater down to a hybrid filtration station that integrates within the highway roundabout and that serves as a connective pedestrian crossing between the two sides of the highway. This station redistributes water to the lower fields, allowing irrigation and clean water flow down to the sea.

The third group identified the longitudinal potential of the site as a connective spine, building on commercial, educational, and leisure activities present there. Their proposal imagined a meandering and organically formed spine that connects laterally across the different programs of the sites, and allows for pedestrians, bicycles, and public transport. This connective unfolding strip links to new interstitial programs that activate the residual lots throughout the site with various forms of landscape and leisure (Fig. 11). This spine would equally help reactivate existing programs of beach resorts, restaurants, and retail that are spread on distinct portions of the site. At the macro level, the students integrated revived landscapes that overtake existing abandoned structures and the polluting powerplant and 


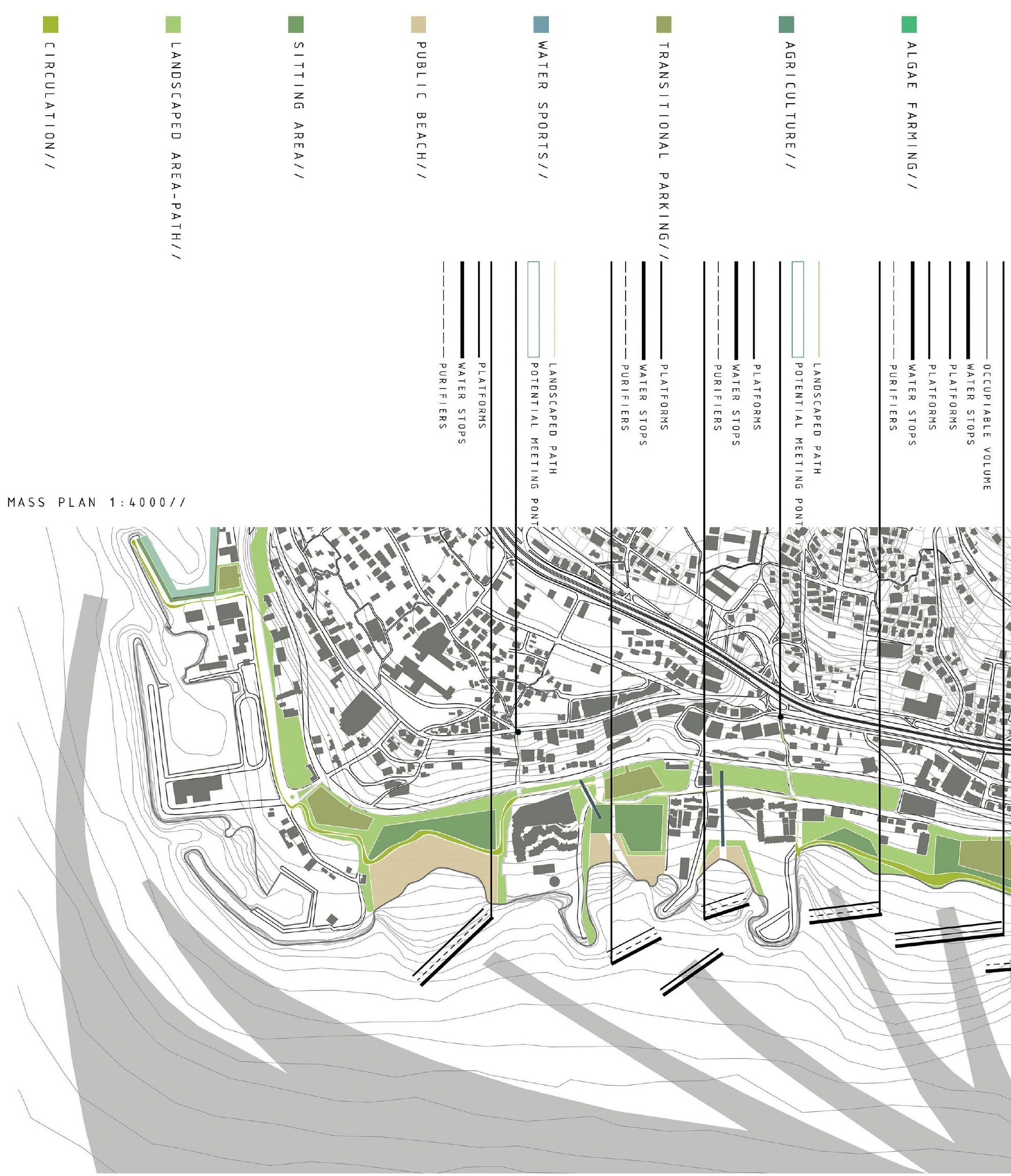

Figure 6. Project 1: Macro re-naturalization and wave current flows. 


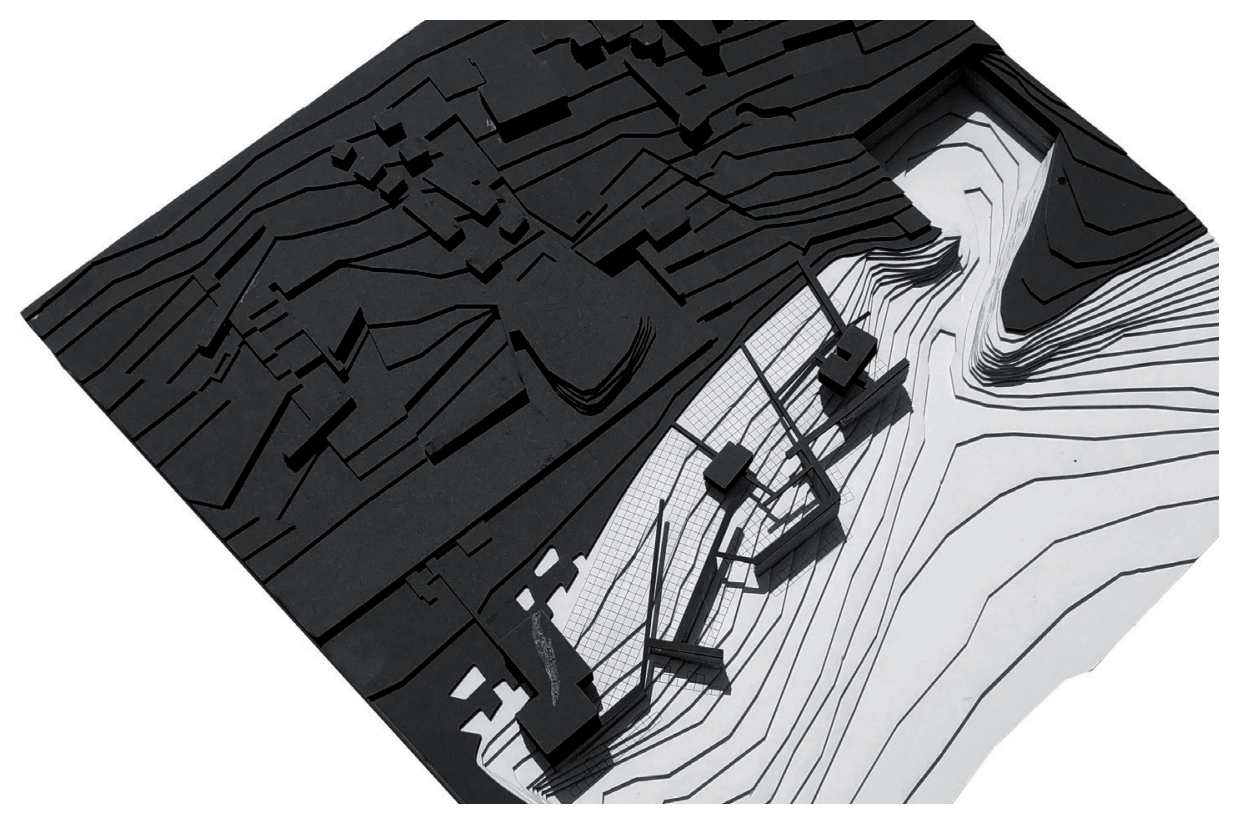

Figure 7. Project 1: Physical model showing hybrid platforms and barrier piers.
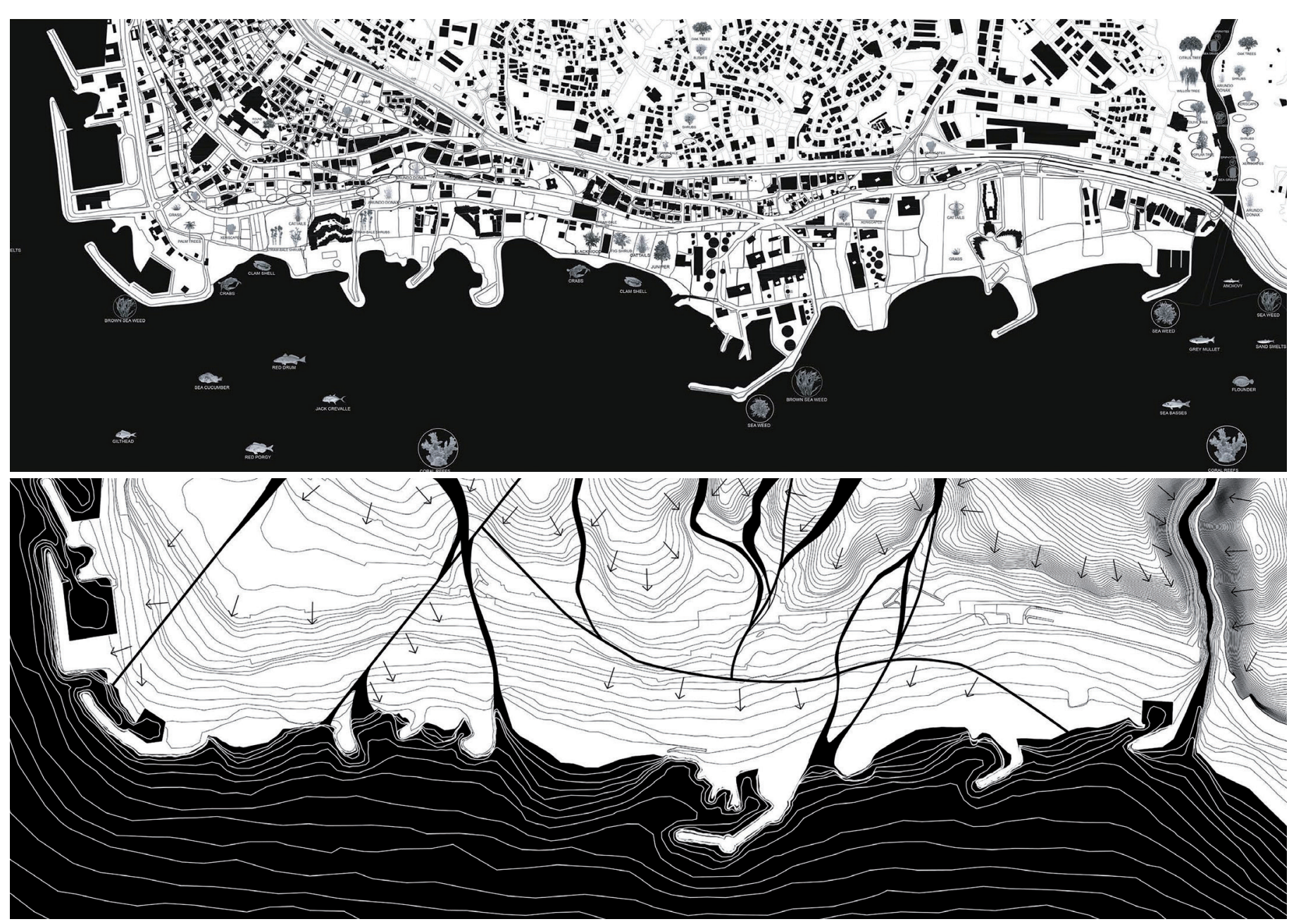

Figure 8. Project 2: Flora/Fauna, pollution, and watershed. 


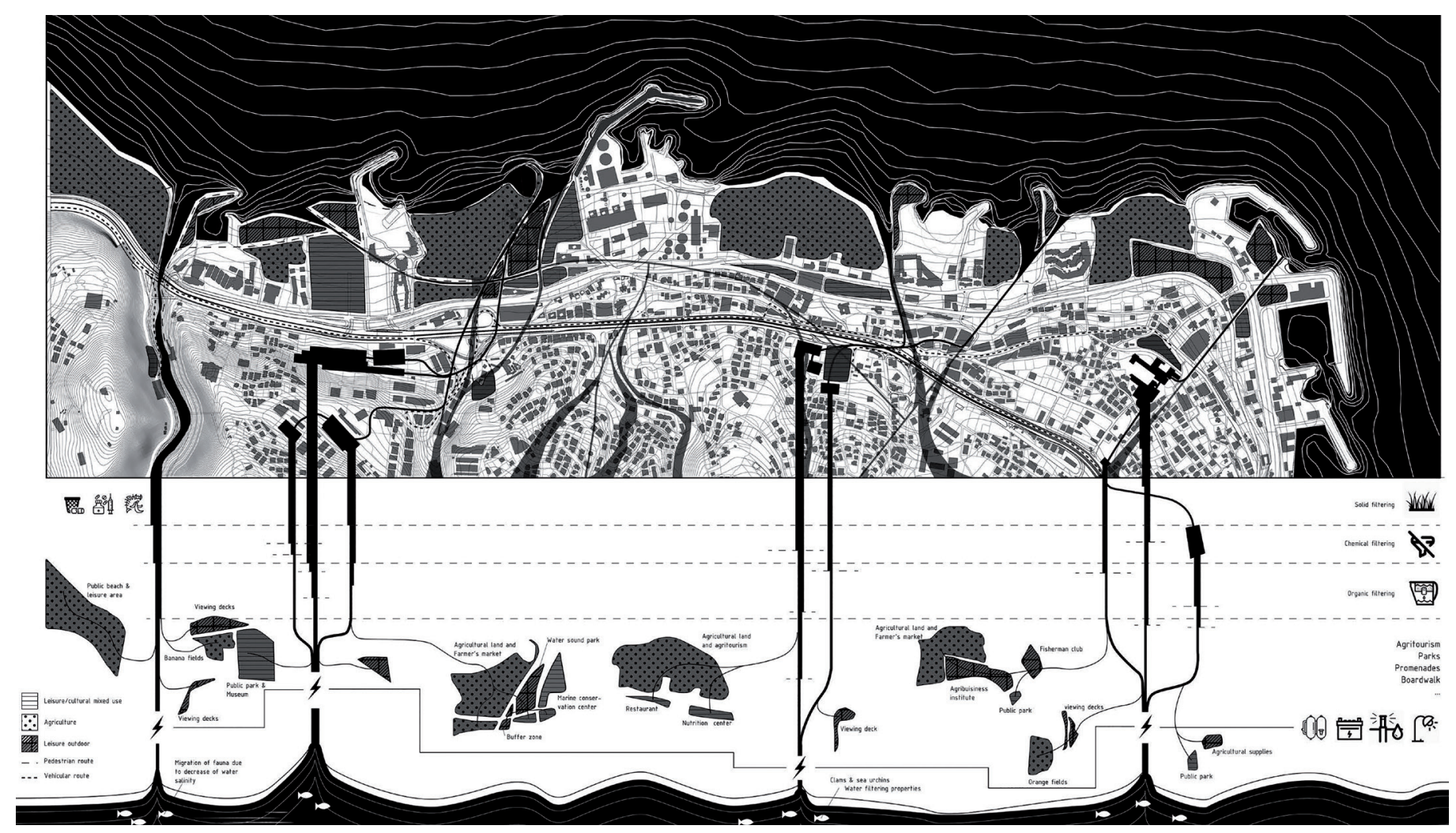

Figure 9. Project 2: Rethinking the coast as an ecological water field.

Figure 10. Project 2: Productive landscape, new delta condition, and water distribution.

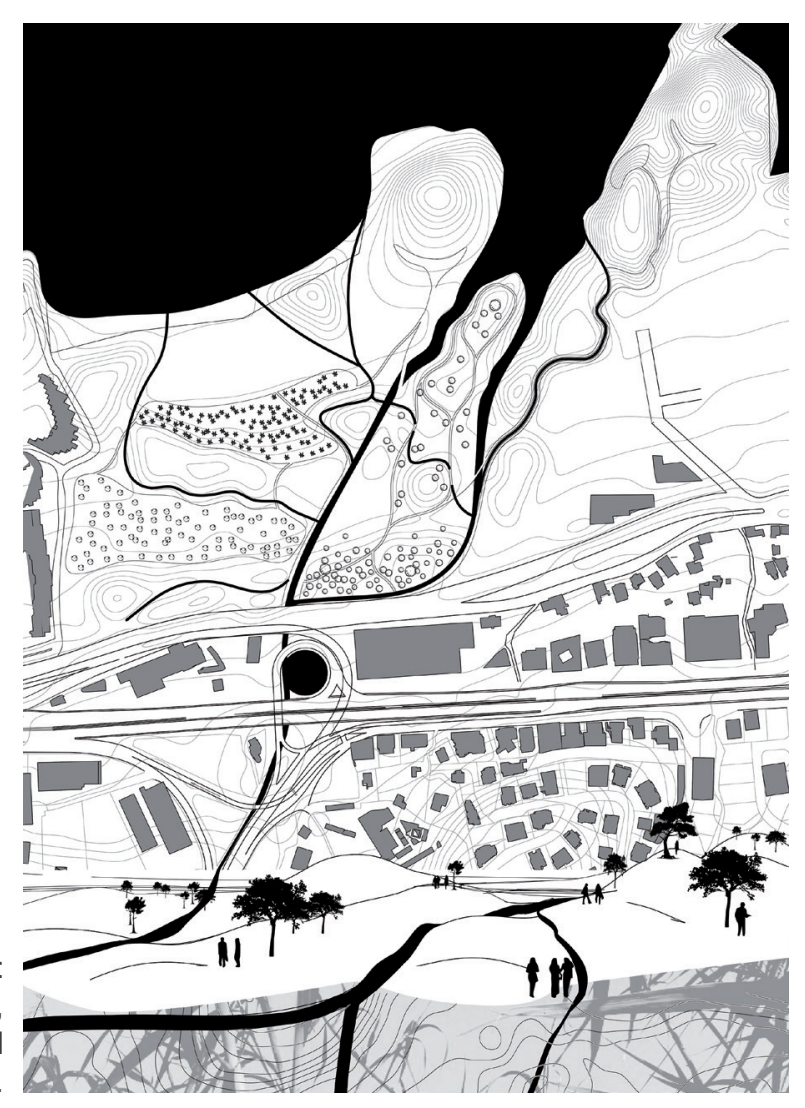




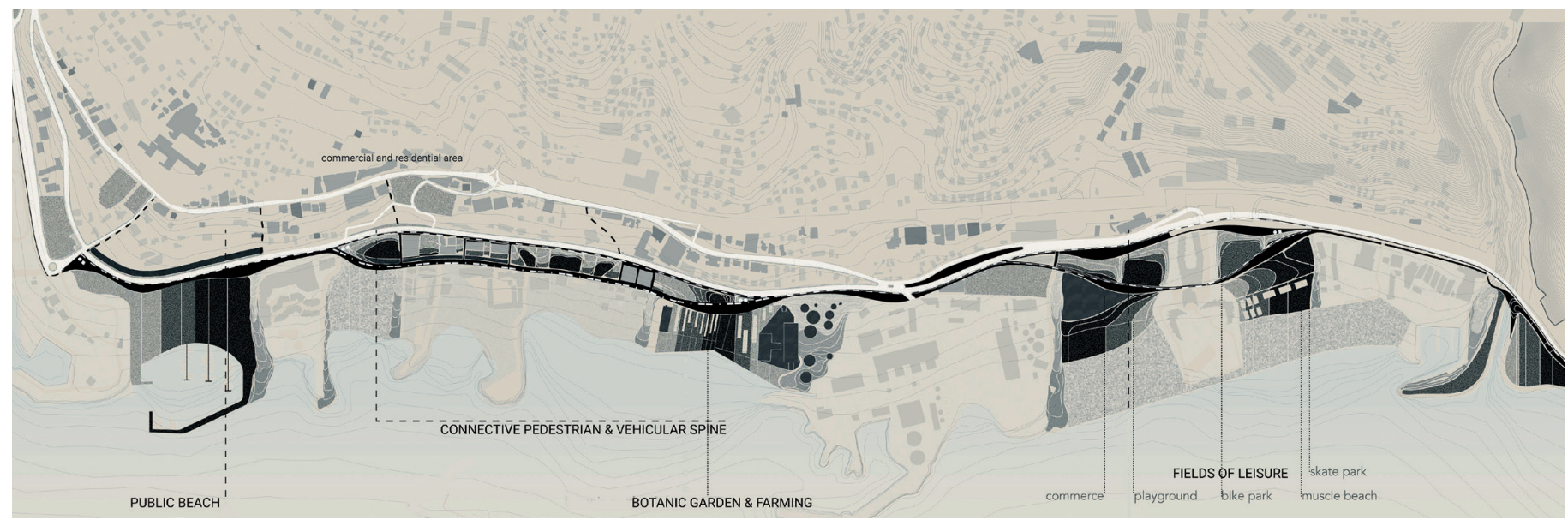

Figure 11. Project 3: Macro leisure strategy with connective spine.

elaborated on new forms of leisure that adapt to the various conditions of the interstitial sites. These programs varied from an informal public beach area, a reconstituted agricultural field area, a botanical garden, a water sports, playground, and skate park area linking to the adjacent resorts. Their developed mid-scale proposal focused on the botanical garden (Fig. 12), developed as a field of rolling landscapes with native flora. The hybrid scheme integrated with abandoned factory buildings on site, inserting in them indoor programs that support the botanical garden from exhibition spaces, a visitor's center, to a gift shop (Fig. 13).

The fourth project built upon disparate public domains (from private roads, old water channels, and footpaths) as operative mechanisms to reactivate the area and the landscape. In identifying all public domain slivers from cadastral maps, the students defined possible zones of disconnected interventions, and turned their reading into a notational device for intervening with connections and intersections with existing enclosed programs. At a macro scale, their intervention looked at environment and new leisure as economical potentials, where outdoor and indoor programs become a field of games with point collection, labelled as a "casino" landscape (Fig. 14). Their proposal included the transformation of the power plant into a clean energy station, and the insertion of new programs from market extension, student hub, to outdoor gaming that serve as economic activities to link and activate related programs on site. The scheme also included transportation arteries that extend to neighboring coastal areas, with dedicated bus routes, and pedestrian and biking paths. Each of their various interventions dissected the landscape into re-stitched public access points and landscape passages, reshaping existing boundaries and usage of the public beach (Fig. 15). Within these land carvings, programs of gaming, views, and connection to neighboring resorts occur, where visitors engage in outdoor and indoor leisure activities, as they transverse the site down to the public beach. 


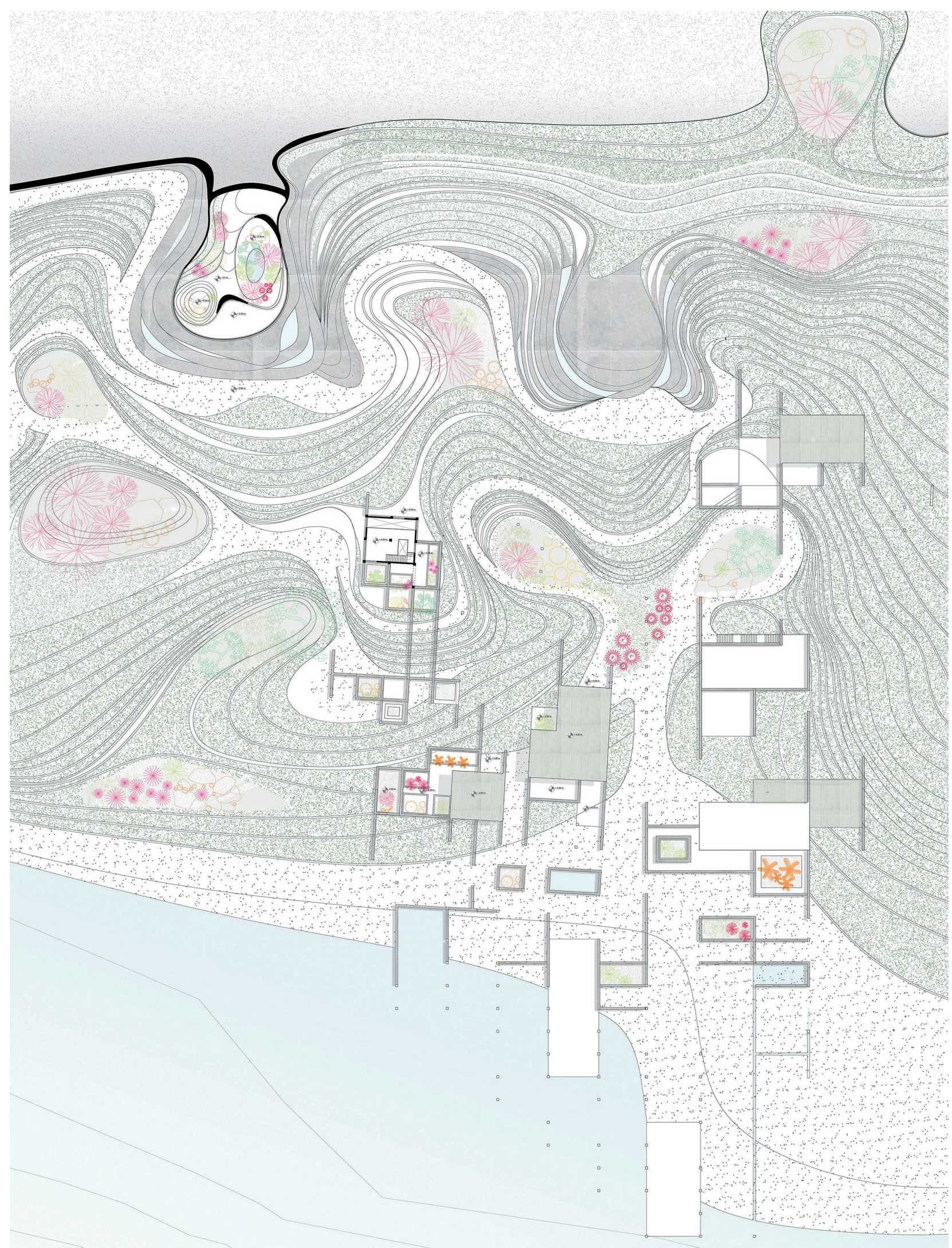

Figure 12. Project 3: Botanical garden landscapes and spaces with intervention on existing factory. 


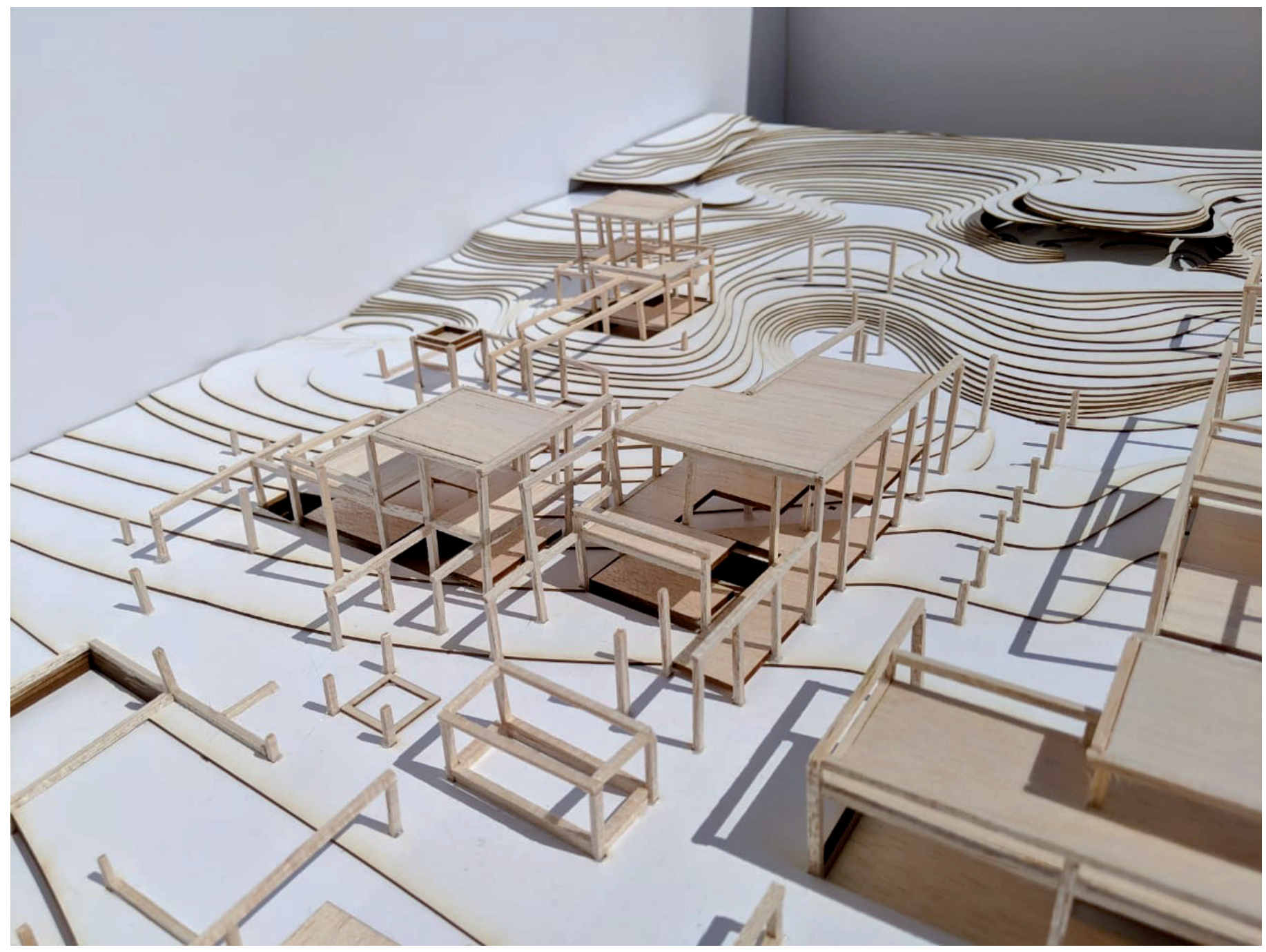

Figure 13. Project 3: Physical model: Between landscape and field.

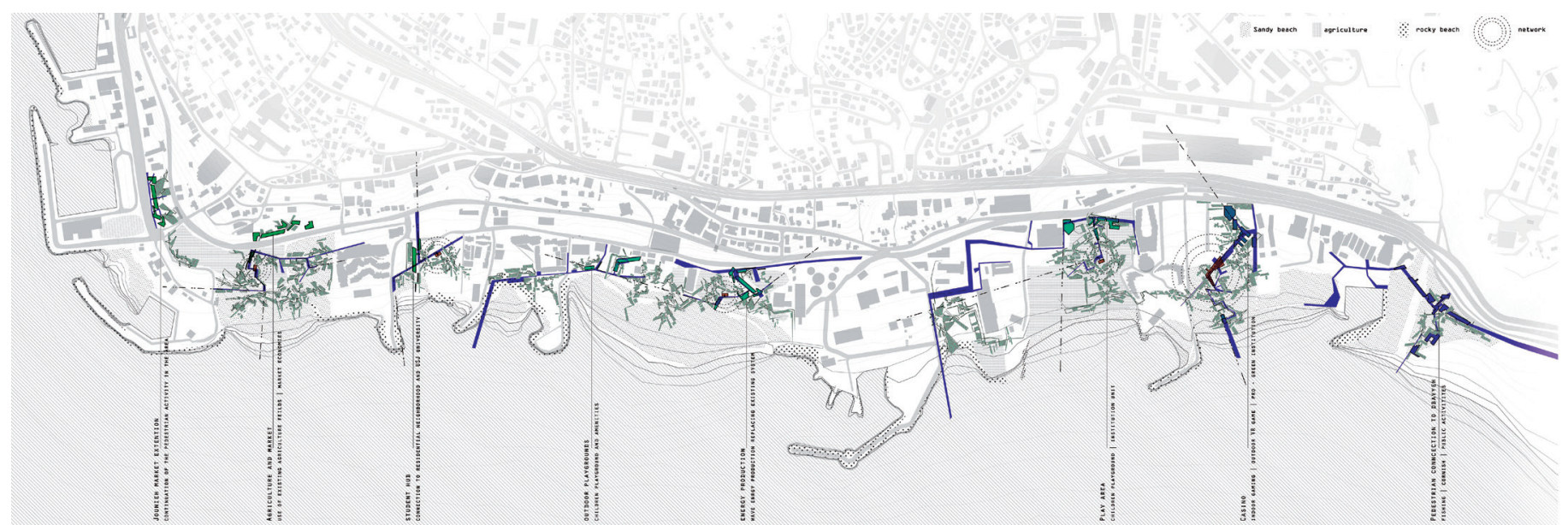

Figure 14. Project 4: Re-envisioning public domains as a macro strategy. 


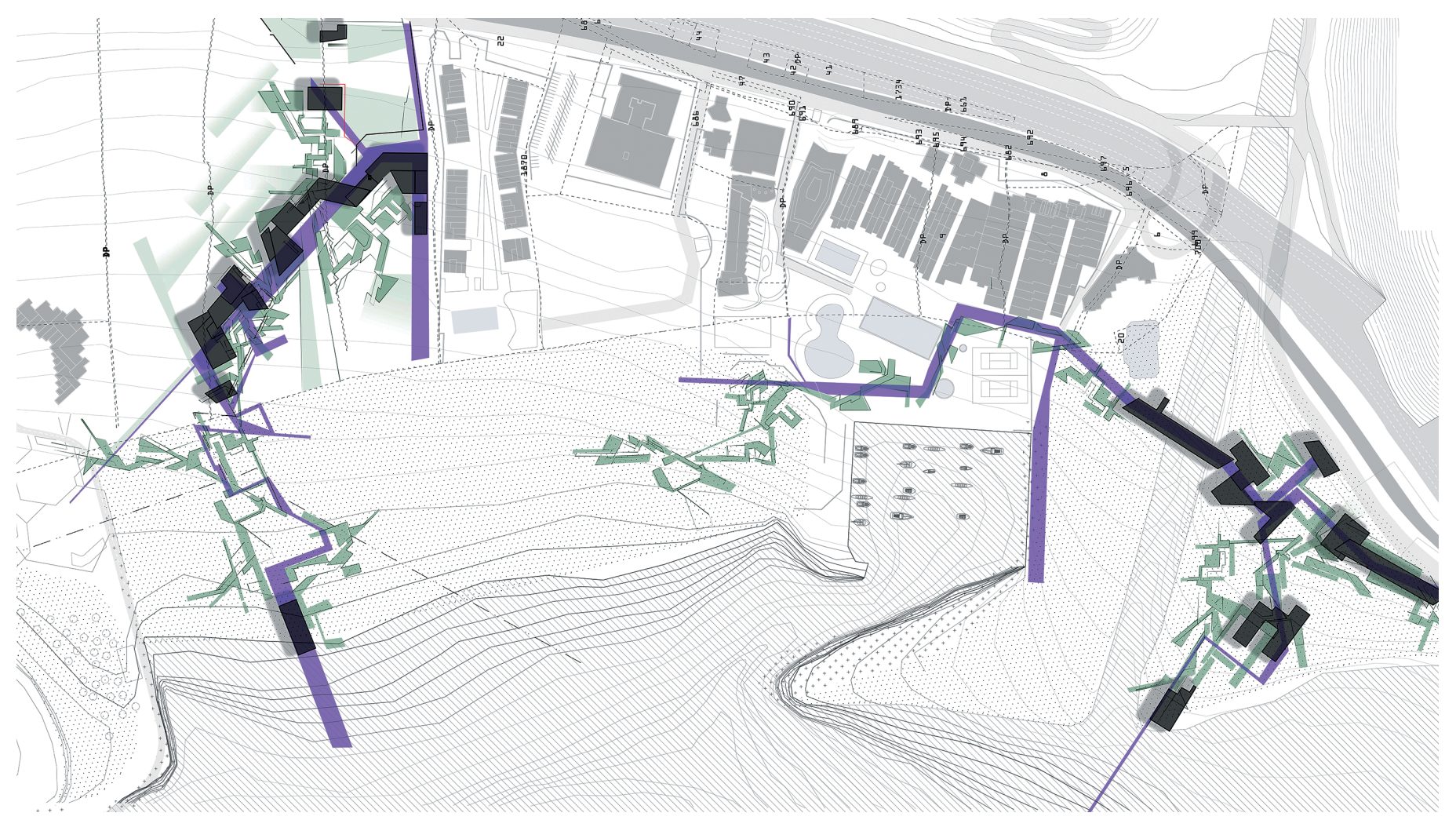

Figure 15. Project 4: Landscape as game reshaping resort boundaries.

\section{CONCLUSION}

From a pedagogical perspective, the studio allowed the students to engage in a holistic manner with an ecological design framework on an uncharted site by the coast. The research and mappings developed by the students enabled them to understand the different social, cultural, environmental, and infrastructural layers of Zouk, and their implication on the area's current state.

From a design and formal level, the scalar method allowed students not only to investigate the different layers of the site, but also to tackle them at multiple levels of complexity. Macro issues, such as dynamic flows of water shed or sea currents, or public domain disintegration from a cadastral level, became the design instigators for the students' macro strategy, and the regulating system for their new synthetic field. Through zooming in, the resolution of understanding site specificities and disconnections, including the resorts' thresholds, coastal edge morphologies and environmental conditions, and abandoned industrial structures, became a key aspect to interconnect the different site ecologies, and formulate a unified vision for the area. Furthermore, the methodology of using abstract "field" models as a way to induce formal and typological alternatives for the site, enabled students to conceive their projects as continuous systems, encompassing multiple public activities and productive landscapes. 
From a programmatic and ecological level, the student work presented here each approached the ecological problematics of Zouk from a different perspective. Initiating from the toxicities affecting the site, the first project enhances the coastal rejuvenation and the re-growth of marine ecosystems, while promoting filtration through landscapes and bioswales as alternatives. The second project develops new regulating landscapes that enhance water shed and water collection for the area, while promoting agri-tourism and marine leisure programs for the general public. It also centralizes water infrastructure as a connective pedestrian and vehicular spine, crossing over the highway boundary, and linking back the suburbs to the coast. The third project highlights the site's characteristic as a touristic and commercial spine, building on this potential to propose interstitial interventions and new public, while enhancing the natural environment, and addressing slow and fast mobility issues. Finally, the fourth project, expands on the notion of public domain, turning the residual slivers into activated areas that stitch the different site thresholds through a new gaming landscape, and promoting a new economic model for the site, with transportation network, and playful landscapes.

Despite the fact that some projects delved into more conceptual investigations that might seem unrealizable, however they offer speculative alternatives that could set the way for new modes of productivity for the site. Whether it is productivity through water, energy, agricultural or marine produce, the different projects allow the possibility of new forms of leisure and landscapes to take shape in the site, while retaining its existing systems and ecologies.

The studio thus attempted to form a new synthetic alternative, developing from the site's existing natures and its latent differences as moments of opportunity. It attempted to question the site's divisions and barriers at their different scales of disconnection, suggesting new fluxes that can override current practices, and reposition the area as a potentially biodiverse field serving both the community and the natural environment. The aim was to give a viable alternative that turns away from real estate as the only operative mode of development, to suggest instead other productive and economic practices that can sustain the area and its ecology. By imagining new modes of development, production, and leisure, and by situating landscape and architecture as inherently symbiotic practices through an agile ecological approach, the studio work presented here aimed for a possible re-naturalized and conjoined future for this neglected coast of Zouk. 


\section{Notes}

1. Rem Koolhaas, "Whatever Happened to Urbanism?," Design Quarterly, no. 164 on "Sprawl" (Spring, 1995): 28-31.

2. DAR-IAURIF, "National Physical Master Plan of the Lebanese Territory (NPMPLT),"

(December 2005): I-18, http://www.databank.com.lb/docs/NPMPLT2.pdf.

3. MOE/UNDP/ECODIT, "State and Trends of the Lebanese Environment Report (SOER 2010)," 2011, 192-93 https://www.lb.undp.org/content/dam/lebanon/docs/Energy\%20 and\%20Environment/Publications/SOER_en.pdf.

4. The fifteen year civil war in Lebanon was a devastating period of conflict that started in 1975 until 1990, with immense destructive impact on Beirut and its surrounds, resulting in massive migrations out of the capital to outer peripheral suburbs leading to the rapid densification and uncontrolled urbanization of a once more natural and rural coastal environment.

5. UN-Habitat, "National Urban Policies Programme in Lebanon Diagnosis Report," (2018): 24-25, https://unhabitat.org/national-urban-policies-programme-in-lebanon-diagnosis-report. 6. Eric Huybrechts, "Architecture and Urban Developments on the Central Lebanese Coast," in Architecture Re-introduced: New Projects in Societies in Change, ed. Jamal Abed, (Geneva: The Aga Khan Award for Architecture, 2004), 101-03.

7. Monica Basbous, Abir Saksouk, and Nadine Bekdache, "The General Directorate of Urban Planning: Senseless Practice Between the National Master Plan, General Master Plans, Exceptions, and Decisions," Legal Agenda, February 2018, https://publicworksstudio. com/sites/default/files/article2_en.pdf.

8. DAR-IAURIF, footnote 3, p. I-18.

9. Elias El Khoury, "L'évolution des complexes touristiques balnéaires et de montagne au Mont Liban" (Lille, Fr.: Atelier National de Reproduction des Thèses, 2003), 170-72.

10. Nadine Bekdache (Public Works Studio), "Planning Zouk Mikael: Ignoring the Power

Plant of Death,” Jadaliyya, November 2018, https://www.jadaliyya.com/Details/38069.

11. Ibid.

12. Ibid.

13. Stan Allen, "Banham's Material Ecologies," in Journal of Architectural Education 71, no. 2 (2017): 262-63.

14. Ignasi de Solà-Morales, "Terrain Vague," in Anyplace, ed. Cynthia C. Davidson

(Cambridge MA, USA: 1995): 118-23.

15. Mohsen Mostafavi, "Why Ecological Urbanism? Why Now?," in Ecological

Urbanism (Baden, Switz.: Lars Müller Publishers, 2010), 12-53.

16. James Corner, "Organizational Ecologies," in Going Live: From States to Systems, ed. Pierre Belanger (New York: Princeton Architectural Press, 2015), 77.

17. Michelle Laboy, "Landscape as a Conceptual Space for Architecture: Shifting Theories and Critical Practices," in The Plan Journal 0, no. 0 (2016): 77-96.

18. Anna Souter, "Run Rewild: Reinstating Nature," in The Architectural Review, no. 1467 (December 2019/January 2020), 55-57.

19. Kate Orff, Towards an Urban Ecology (New York: The Monacelli Press, 2016), 7-16.

20. Ibid., 19.

21. Ibid., 81-83. 


\section{Acknowledgments}

This paper discusses the work and approach of the undergraduate Vertical Studio: Ecologies of Leisure, that was given Spring 2019 at the Department of Architecture and Design at the American University of Beirut. The studio was co-taught with Nicolas Fayad (Senior Lecturer). The research on Zouk and its beach resorts was supported by the American University of Beirut's University Research Board (URB) - under the 2018 grant "Beach Mega-complexes as Peri-urban Constructs of Living and Leisure."

\section{Credits}

Figures 1, 2 and 4: mappings by (C) the Author.

Figure 3: mapping by (@) the Author, photography by @ Rami Rizk.

Figure 5: work by @ Karim Rifai and Nawal Al Rahbani.

Figures 6 and 7: Project 1, student work by Lea Saad and Sarah Al Harouny.

Figures 8-10: Project 2, student work by Karim Rifai and Nawal El Katoul Al Rahbani.

Figures 11-13: Project 3, student work by Nicol Yamin and Nicolas Abou Haidar.

Figures 14 and 15: Project 4, student work by Salem Shamia and Sabine Doueiry.

Carla Aramouny, architect and Assistant Professor at American University of Beirut, Department of Architecture and Design, holds a MArch from the University of Pennsylvania and a BArch from the Lebanese American University. Her practice earned her international and local awards. Her research and teaching tackle intersections of architecture with the expanded environment and focuses on hybrid architecture and infrastructure, as well as digital/analog shifts in making and representation. Her work has been presented and published in several international conferences and exhibitions. She is also founder and director of ArD Tech Lab, a digital fabrication unit at AUB. Email: ca38@aub.edu.lb 